\title{
Use of pre-operative anxiety score to determine the precise dose of butorphanol for intra-operative sedation under regional anesthesia: A double-blinded randomized trial
}

\author{
BIJIA SONG ${ }^{1}$, YANCHAO YANG ${ }^{1}$, XIUFEI TENG ${ }^{1}$, YANG LI $^{1}$, WENYA BAI $^{2}$ and JUNCHAO ZHU ${ }^{1}$ \\ ${ }^{1}$ Department of Anesthesiology, Shengjing Hospital of China Medical University, Shenyang, Liaoning 110000; \\ ${ }^{2}$ Department of Anesthesiology, The First Affiliated Hospital of Kunming Medical University, \\ Kunming, Yunnan 650032, P.R. China
}

Received April 22, 2019; Accepted August 30, 2019

DOI: $10.3892 /$ etm.2019.8040

\begin{abstract}
A randomized double-blinded controlled trial was performed to explore the association between pre-operative anxiety and intra-operative butorphanol requirement to evaluate the precise sedative requirement and to confirm the sedative effect of butorphanol in patients receiving lower-limb orthopedic surgery. The Amsterdam pre-operative anxiety and information scale and the Ramsay sedation score (RSS) were used to assess the patients' pre-operative anxiety score and sedation state during surgery. Patients were divided into two groups according to their pre-operative anxiety score prior to administration of pre-medication. Patients in each group were randomly divided into a butorphanol group and a $0.9 \%$ saline group. A total of 142 patients were enrolled and 131 patients were analyzed. The sedation scores of patients with high pre-operative anxiety in the $0.9 \%$ saline group were lower than those in the butorphanol group at each time-point after infusion. An increased pre-operative anxiety score predicted an increased duration to reach an RSS of 4 for an acceptable level of sedation $\left(r^{2}=0.887, \mathrm{P}<0.0001\right)$. In conclusion, butorphanol had a good sedative effect on patients with pre-operative anxiety. The following formula was proposed: Precise dose of butorphanol $(\mu \mathrm{g} / \mathrm{kg})=15.26+(0.14 \mathrm{x}$ pre-operative anxiety score), which may provide an improvement for patients exhibiting a high level of pre-operative anxiety. The trial was
\end{abstract}

Correspondence to: Professor Junchao Zhu, Department of Anesthesiology, Shengjing Hospital of China Medical University, 39 Huaxiang Road, Tiexi, Shenyang, Liaoning 110000, P.R. China E-mail: zhujunchao1@hotmail.com

Abbreviations: APAIS, Amsterdam pre-operative anxiety and information scale; RSS, Ramsay sedation score; NIBP, non-invasive blood pressure; $\mathrm{SpO}_{2}$, peripheral oxygen saturation; MAP, mean arterial pressure; HR, heart rate; VAS, visual analogue scale

Key words: butorphanol, pre-operative anxiety, precise dose, intra-operative sedation registered prior to patient enrollment at clinicaltrials.gov on 20.01.2018 (trial registration no. NCT03429179).

\section{Introduction}

Pre-operative anxiety is a commonly encountered unpleasant and stressful state prior to surgery, which may negatively affect treatment outcomes, lead to an increased demand for anesthetics during surgery and enhance vulnerability to infection (1). Previous studies have proved that high pre-operative anxiety predicts increased intra-operative sedative requirements (2). Effective intra-operative sedation is required to relieve anxiety, as well as for patient cooperation and satisfaction with the surgery.

Butorphanol is a synthetic opioid with partial agonist action at the $\mu$-opioid and $\kappa$-opioid receptors (3); it has analgesic and sedative effects and only few side effects, low addiction potential and low toxicity (4). The World Health Organization guidelines also recommend the use of butorphanol as an adjunctive anesthetic for intra-operative sedation and post-operative pain relief (5).

Several studies have reported on sedative drugs commonly used during surgery $(2,6,7)$. However, few studies have been performed on sedation with butorphanol in patients with pre-operative anxiety. Furthermore, a formula to predict the precise butorphanol requirement to maintain patients with a high pre-operative anxiety score in an adequate sedative state has remained to be determined.

In the present study, patients who were scheduled for orthopedic procedures under regional anesthesia were selected and prior to the surgery, their pre-operative anxiety score was evaluated by using the Amsterdam pre-operative anxiety and information scale (APAIS). It was hypothesized that there is an association between the APAIS score and the duration of reaching adequate sedation, which can potentially be used to predict the requirement of butorphanol.

\section{Patients and methods}

Subjects. The inclusion criteria were as follows: i) Chinese male or female patients aged $18-75$ years; ii) American Society 
of Anaesthesiologists physical status I or II (8); iii) scheduled for elective lower limb orthopedic procedures under regional anesthesia at Shengjing Hospital of China Medical University (Shenyang, China) between March 2018 and March 2019. The exclusion criteria were as follows: i) Central nervous system disease; ii) cardiovascular disease; iii) autonomic nervous system disease; iv) long-term use of analgesic, sedative or anti-anxiety drugs; vi) psychosis or a language communication disorder; vii) patient did not provide informed consent.

Following assessment of 155 patients for eligibility, 13 patients were excluded based on the above-mentioned criteria. Finally, 142 patients were enrolled as eligible subjects. After evaluating the patients' pre-operative anxiety score by using the APAIS scale (9-12), as well as a computer-generated sequence of random numbers and a sealed-envelope technique, 75 patients in the high pre-operative anxiety group (pre-operative anxiety score $>10$ ) were randomized to receive one of the two treatments (high-anxiety butorphanol group, $\mathrm{n}=38$; high-anxiety $0.9 \%$ saline group, $\mathrm{n}=37$ ) and 67 patients in the low pre-operative anxiety group (pre-operative anxiety score $\leq 10$ ) were also randomized to receive one of the two treatments (low-anxiety butorphanol group, $n=34$; low-anxiety $0.9 \%$ saline group, $\mathrm{n}=33$ ). Following completion of the study, 5 patients in the high pre-operative anxiety group were excluded from the study, comprising 2 patients who did not reach a Ramsay Sedation Score (RSS) of 4 during the operation (13), 2 patients who received rescue analgesic and 1 patient with incomplete data. Furthermore, 6 patients in the low pre-operative anxiety group were excluded from the study, comprising 2 patients with incomplete data, 1 patient with inadequate anesthesia and 3 patients who received rescue analgesic. Therefore, the data from 36 patients in the high-anxiety butorphanol group and 34 patients in the high-anxiety $0.9 \%$ saline group were analyzed in the present study. Furthermore, the data from 32 patients in the low-anxiety butorphanol group and 29 patients in the low-anxiety $0.9 \%$ saline group were analyzed in the present study (Fig. 1).

Study design. This study was approved by the Human Research Ethical Committee of Shengjing Hospital (Shenyang, China; IRB registration no. 2018PS254K) and written informed consent was obtained from all subjects participating in the trial. The trial was registered prior to patient enrollment at clinicaltrials.gov (no. NCT03429179; principal investigator, Bijia Song; date of registration, 20.01.2018).

In the present study, the APAIS was used by an experimental assistant to evaluate the degree of pre-operative anxiety of patients enrolled in the study prior to administration of pre-medication. According to the total anxiety score on the APAIS, patients were divided into a high pre-operative anxiety group (pre-operative anxiety score $>10$ ) and a low pre-operative anxiety group (pre-operative anxiety score $\leq 10$ ). Although a previous study have stated that it was acceptable to not provide sedation for this type of lower-limb surgery under local anesthesia (14), patients enrolled into the present study were exhibiting pre-operative anxiety and it was considered ethical to provide sedation. Preliminary experiments performed by our group indicated no statistically significant differences in RSS after pre-operative intramuscular injection of low-dose midazolam for patients with different anxiety levels, which was confirmed by statisticians (15). Thus, intramuscular midazolam $(0.05 \mathrm{mg} / \mathrm{kg})$ as a pre-medication was administered to patients $60 \mathrm{~min}$ prior to transfer to the operating room. All patients were routinely prepared according to the requirements of regional anesthesia. Upon arrival in the operating room, standard monitoring, including an electrocardiogram, non-invasive blood pressure (NIBP) and peripheral oxygen saturation $\left(\mathrm{SpO}_{2}\right)$, were applied. Regional anesthesia was then implemented through the L2-3 or L3-4 intervertebral space and $0.5 \%$ bupivacaine was injected into the subarachnoid cavity according to the age and weight of the patients until the block plane reached T8-T10. In the high-anxiety butorphanol group and low-anxiety butorphanol group, patients received an intravenous (i.v.) loading dose of $15 \mu \mathrm{g} / \mathrm{kg}$ butorphanol $5 \mathrm{~min}$ prior to the beginning of the surgery, followed by infusion of $7.5 \mu \mathrm{g} / \mathrm{kg} / \mathrm{h}$ butorphanol and the infusion was stopped when the RSS reached 4 . The high-anxiety $0.9 \%$ saline group and the low-anxiety $0.9 \%$ saline group received an infusion of the same volume of $0.9 \%$ saline. Ramosetron $(0.3 \mathrm{mg})$ was administered prophylactically at the end of the surgery. The anesthesiologist connected the i.v. microcomputer-controlled drug-infusion devices to the patients (Kelijianyuan Med. Co.). The study was double-blinded for all of the researchers, physicians who collected the data, the nurses and the staff who prepared the medications. Each device syringe was filled with butorphanol or $0.9 \%$ saline from similar ampoules to the same volume. The timeline of the experimental procedure is provided in Fig. 2.

Experimental data collection. NIBP, mean arterial pressure (MAP) and heart rate (HR) were recorded 10 min after entering the operating room (baseline, $\mathrm{T}_{0}$ ), and at $5 \mathrm{~min}\left(\mathrm{~T}_{1}\right)$, $10 \mathrm{~min}\left(\mathrm{~T}_{2}\right), 15 \mathrm{~min}\left(\mathrm{~T}_{3}\right)$ and $30 \mathrm{~min}\left(\mathrm{~T}_{4}\right)$ after the commencment of i.v. butorphanol infusion of. Hypotension (MAP $<70 \mathrm{mmHg}$ ) was treated with fluid boluses and $6 \mathrm{mg}$ i.v. boluses of ephedrine, while bradycardia $(\mathrm{HR}<50 \mathrm{bpm})$ was treated with $0.6 \mathrm{mg}$ i.v. atropine. Respiratory depression was defined as a respiratory rate of $<8$ breaths/min or an $\mathrm{SpO}_{2}$ of $<90 \%$ on room air. Patients were given supplemental $\mathrm{O}_{2}$ via face mask at $61 / \mathrm{min}$ if the $\mathrm{SpO}_{2}$ decreased $<90 \%$. The RSS in the four groups was recorded at $10 \mathrm{~min}$ after entering the operation room and at 5,10,15 and 30 min after infusion of butorphanol or $0.9 \%$ saline, and the duration for the RSS to reach 4 in the high-anxiety butorphanol group and the low-anxiety butorphanol group was also recorded. In the post-operative period, pain scores were assessed on the visual analogue scale (VAS) (16) every hour up to $6 \mathrm{~h}$ and then every $2 \mathrm{~h}$ up to $24 \mathrm{~h}$. Patients were given flurbiprofen axetil $50 \mathrm{mg}$ as a rescue analgesic and then excluded from the analysis. Adverse events, including nausea/vomiting, dizziness, bradycardia and respiratory depression were recorded at the same time-points as the VAS scores and treated accordingly.

Evaluation of pre-operative anxiety. The APAIS is a questionnaire to assess patients' pre-operative anxiety score, which was developed in 1996 by the Dutch clinician Moerman (9). The APAIS comprises 6 items rated on a five-point Likert scale, which includes two scales: Anxiety (items 1,2,4 and 5) and requirement for information (items 3 and 6) (10,11). The maximal total APAIS score is 30 ; this is comprised of a 


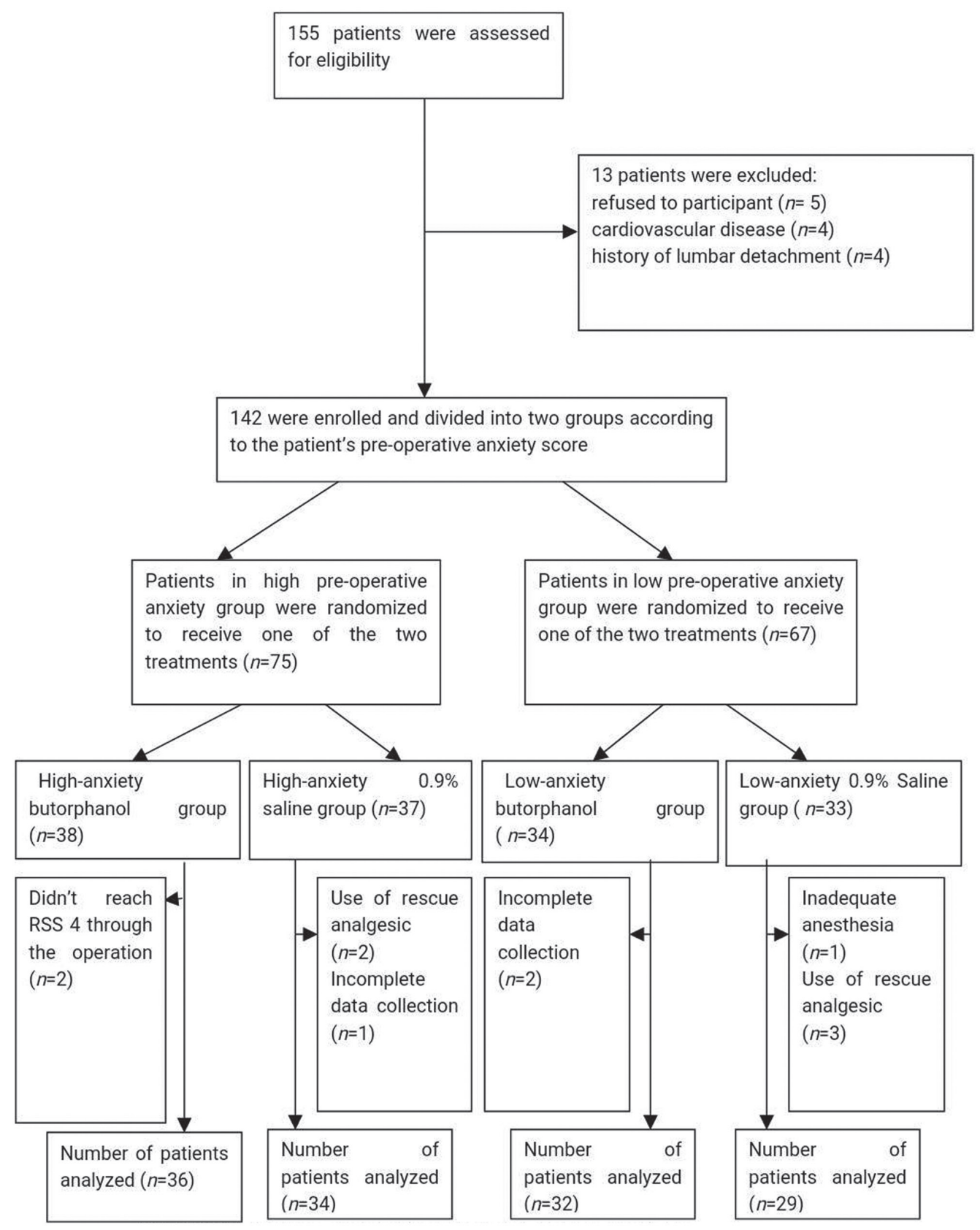

Figure 1. Flow diagram for the inclusion of patients in the present study. RSS, Ramsay Sedation Score.

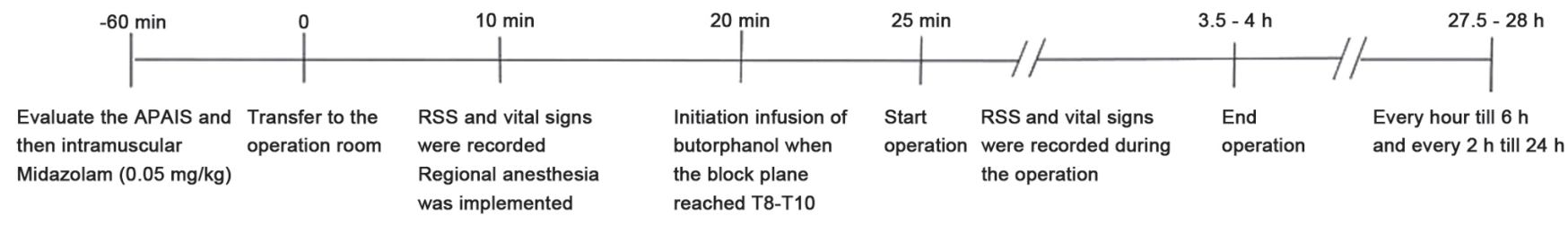

Figure 2. Timeline of the experimental procedure. RSS, Ramsay Sedation Score; VAS, visual analogue scale; APAIS, Amsterdam pre-operative anxiety and information scale.

maximum score expressing the patient's requirement for information of 10 and a maximal score of the two items concerning anxiety regarding anesthesia and surgery of 10 each, resulting in a maximal score of 20 for total anxiety (APAIS-A-T). In the present study, APAIS-A-T $>10$ was used as a cut-off to define patients with high anxiety, with a higher score indicating a higher level of anxiety (12).

Evaluation of sedation. The depth of sedation was determined based on the RSS scale (13), as follows: 1, Anxious 
Table I. Patient characteristics.

\begin{tabular}{|c|c|c|c|c|c|}
\hline \multirow[b]{2}{*}{ Item } & \multicolumn{2}{|c|}{ High pre-operative anxiety group } & \multicolumn{2}{|c|}{ Low pre-operative anxiety group } & \multirow[b]{2}{*}{ P-value } \\
\hline & $\begin{array}{l}\text { Butorphanol group } \\
\qquad(\mathrm{n}=36)\end{array}$ & $\begin{array}{l}0.9 \% \text { saline group } \\
\quad(\mathrm{n}=34)\end{array}$ & $\begin{array}{l}\text { Butorphanol group } \\
\qquad(\mathrm{n}=32)\end{array}$ & $\begin{array}{l}0.9 \% \text { saline group } \\
(\mathrm{n}=29)\end{array}$ & \\
\hline Sex & & & & & 0.888 \\
\hline Male & $17(47.2)$ & $14(41.2)$ & $13(40.6)$ & $11(37.9)$ & \\
\hline Female & $19(52.8)$ & $20(58.8)$ & $19(59.4)$ & $18(62.1)$ & \\
\hline Age (years) & $47.1 \pm 16.8$ & $47.3 \pm 16.0$ & $41.5 \pm 14.2$ & $41.0 \pm 12.3$ & 0.172 \\
\hline Weight (kg) & $65.8 \pm 3.0$ & $68.6 \pm 10.6$ & $69.8 \pm 8.3$ & $66.0 \pm 4.1$ & 0.069 \\
\hline Duration of surgery (min) & $83.3 \pm 15.8$ & $84.0 \pm 16.5$ & $85.2 \pm 18.4$ & $86.5 \pm 16.4$ & 0.877 \\
\hline Type of surgery & & & & & 0.283 \\
\hline Repair of ligament injury & $15(41.7)$ & $17(50)$ & $11(34.4)$ & $9(31.1)$ & \\
\hline Repair of meniscus injury & $11(30.6)$ & $8(23.5)$ & $10(31.3)$ & $15(51.7)$ & \\
\hline Other & $10(27.8)$ & $9(26.5)$ & $11(34.4)$ & $5(17.2)$ & \\
\hline
\end{tabular}

Values are expressed as the mean \pm standard deviation or as $\mathrm{n}(\%)$.

and agitated or restless or both; 2, cooperative, orientated and tranquil; 3 , responds to commands only; 4 , brisk response to a light glabellar tap or auditory stimulus; 5, sluggish response to a light glabellar tap or auditory stimulus; and 6, no response to a light glabellar tap or auditory stimulus. Patients with a sedation score equal to 4 were considered to have adequate sedation.

Evaluation of patient satisfaction. Patient satisfaction was recorded on 5 levels: a) Agreeable experience; b) neither pleasant nor unpleasant; c) slightly uncomfortable; d) disagreeable experience; e) traumatic experience.

Statistical analysis. SPSS 20.0 statistical software (IBM Corp.) was used for data analysis. Continuous variables are expressed as the mean \pm standard deviation and the Chi-squared test was used to analyse differences in demographic data, postoperative side effects and patient satisfaction between groups. Comparisons between two groups were performed by using an independent-samples Student's t-test. One-way analysis of variance (ANOVA) followed by Bonferroni correction was used for multiple comparisons and Welch's ANOVA followed by Tamhane's T2 post-hoc pairwise comparison was used for multiple groups which did not meet the Levene's test criteria. Linear association analysis was performed between the APAIS score and duration of RSS reaching 4 to calculate an $\mathrm{r}^{2}$ value. $\mathrm{P}<0.05$ was considered to indicate statistical significance.

\section{Results}

Patient characteristics. The patient characteristics are provided in Table I. There were no significant differences among the study groups regarding demographic characteristics, type of surgery or duration of surgery.

Comparison of the RSS among the different groups. The RSS score of the different groups at various time-points is provided in Table II. Of note, there was no significant difference in RSS at 10 min after entering the operating room among the four groups $(\mathrm{P}>0.05)$. The sedation scores of the high-anxiety $0.9 \%$ saline group were lower than those of the high-anxiety butorphanol group at each time-point after infusion $(\mathrm{P}<0.05)$. There were also significant differences between the high-anxiety butorphanol group and the low-anxiety butorphanol group at each time-point after infusion $(\mathrm{P}<0.05)$.

Association between the APAIS score and duration of RSS reaching 4. As presented in Fig. 3, an approximately linear correlation between the APAIS score and duration of RSS reaching 4 was observed. Linear regression analysis revealed an $\mathrm{r}^{2}$-value of 0.887 , suggesting that $88.7 \%$ of the variation in the time taken for the RSS to reach 4 may be accounted for by the APAIS score $(\mathrm{P}<0.0001)$. The regression equation was determined as follows: Duration of reaching adequate sedation $(\mathrm{min})=(1.075 \times$ APAIS score $)+2.081$. According to the butorphanol infusion method applied in the present study, the formula to determine the required dose was as follows: Precise dose of butorphanol $(\mu \mathrm{g} / \mathrm{kg})=15.26+(0.14 \times$ APAIS score $)$.

Comparison of HR and MAP among the different groups. The HR and MAP in the different groups at each time-point are provided in Table III. In the high-anxiety butorphanol group and low-anxiety butorphanol group, the MAP at each time-point was significantly lower than that at the respective previous time-point in the same group $(\mathrm{P}<0.05)$. However, no significant differences were obtained in the high-anxiety $0.9 \%$ saline group and low-anxiety $0.9 \%$ saline group with this regard $(\mathrm{P}>0.05)$. The MAP at each time point in the high-anxiety $0.9 \%$ saline group was higher compared with that in the other three groups. Furthermore, the HR at T0 in the high-anxiety butorphanol group and high-anxiety $0.9 \%$ saline group were higher compared with that in the low-anxiety butorphanol group, though there was no 
Table II. Ramsay Sedation Score.

\begin{tabular}{|c|c|c|c|c|c|}
\hline Group & T0 & $\mathrm{T} 1$ & $\mathrm{~T} 2$ & $\mathrm{~T} 3$ & $\mathrm{~T} 4$ \\
\hline \multicolumn{6}{|c|}{ High pre-operative anxiety } \\
\hline butorphanol group & $1.42 \pm 0.5$ & $1.92 \pm 0.6^{\mathrm{a}}$ & $2.22 \pm 0.5^{\mathrm{a}}$ & $2.42 \pm 0.5^{\mathrm{a}}$ & $3.31 \pm 1.0^{\mathrm{a}}$ \\
\hline $0.9 \%$ saline group & $1.41 \pm 0.5$ & $1.47 \pm 0.5^{\mathrm{a}, \mathrm{b}}$ & $1.53 \pm 0.5^{\mathrm{a}, \mathrm{b}}$ & $1.65 \pm 0.6^{\mathrm{a}, \mathrm{b}}$ & $1.82 \pm 0.6^{\mathrm{a}, \mathrm{b}}$ \\
\hline \multicolumn{6}{|c|}{ Low pre-operative anxiety group } \\
\hline butorphanol group & $1.53 \pm 0.5$ & $2.34 \pm 0.5^{\mathrm{b}}$ & $2.91 \pm 0.8^{\mathrm{b}}$ & $3.47 \pm 0.8^{\mathrm{b}}$ & $4.0 \pm 0.0^{\mathrm{b}}$ \\
\hline $0.9 \%$ saline group & $1.52 \pm 0.4$ & $1.55 \pm 0.5^{\mathrm{a}, \mathrm{b}}$ & $1.66 \pm 0.7^{\mathrm{a}, \mathrm{b}}$ & $1.83 \pm 0.7^{\mathrm{a}, \mathrm{b}}$ & $1.97 \pm 0.5^{\mathrm{a}, \mathrm{b}}$ \\
\hline P-value & 0.665 & $<0.001$ & $<0.001$ & $<0.001$ & $<0.001$ \\
\hline
\end{tabular}

${ }^{\mathrm{a}} \mathrm{P}<0.05$ vs. Low-anxiety butorphanol group; ${ }^{\mathrm{b}} \mathrm{P}<0.05 \mathrm{vs}$. High-anxiety butorphanol group. Values are expressed as the mean \pm standard deviation. T0, $10 \mathrm{~min}$ after entering the operating room; T1, 5 min after intravenous infusing butorphanol; T2, 10 min after intravenous infusing butorphanol; T3, 15 mins after intravenous infusing butorphanol $15 \mathrm{~min}$; T4, $30 \mathrm{~min}$ after intravenous infusing butorphanol.

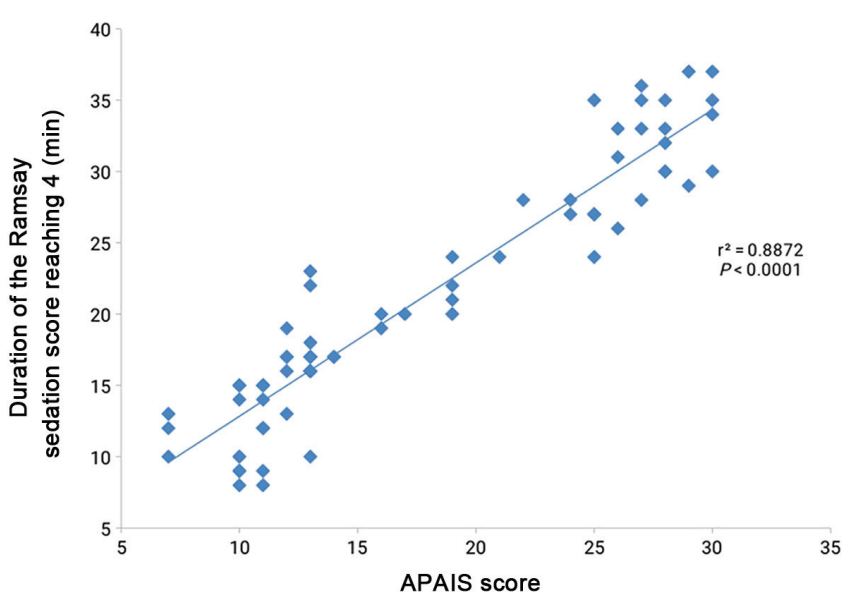

Figure 3. Association between the APAIS score of patients and the duration of the Ramsay sedation score reaching 4 (min). APAIS, Amsterdam pre-operative anxiety and information scale.

significant difference between the low-anxiety $0.9 \%$ saline and the low-anxiety butorphanol groups. The HR value in the high-anxiety $0.9 \%$ saline group remained at a high level during the operation. There was no difference in $\mathrm{SpO}_{2}$ among the four groups during the course of the study (data not shown).

Post-operative recovery. The VAS scores were significantly lower in the butorphanol groups (high-anxiety butorphanol group and low-anxiety butorphanol group) as compared with those in the $0.9 \%$ saline groups (high-anxiety $0.9 \%$ saline group and low-anxiety $0.9 \%$ saline group) throughout the the first $24 \mathrm{~h}$ post operation $(\mathrm{P}<0.05$; Table IV). The differences in adverse events (nausea/vomiting, dizziness, bradycardia and respiratory depression) were statistically insignificant among the four groups (Table IV). However, regarding post-operative patient satisfaction, the rating 'agreeable experience' was significantly more frequently given by the group receiving intra-operative sedation $(\mathrm{P}=0.032)$, while the saline group more frequently provided the rating 'disagreeable experience' $(\mathrm{P}=0.005)$ compared with the respective other group (Table V).

\section{Discussion}

The results of the present study indicated that the requirement of butorphanol for conscious sedation was correlated with the level of pre-operative anxiety in patients receiving lower-limb orthopedic surgery under regional anesthesia. The duration of reaching an adequate sedative state increased approximately linearly with the increase of the APAIS score, which may suggest that for a higher anxiety score, more butorphanol should be used. Previous studies have also reported a correlation between different levels of anxiety and sedative or anesthetic requirement when conscious sedation or anesthesia is used $(2,17,18)$, which was consistent with the results of the present study.

In the present study, APAIS, as a well-established measuring scale, was used to evaluate the level of the patients' pre-operative anxiety, which was also used in previous studies $(19,20)$, and the clinical scoring method used to measure the level of patient sedation was the commonly used RSS scale (21). A sedative state with an RSS of 3 or 4 was considered as an adequate level of sedation (22). Therefore, in the present study, the time taken for the RSS to reach 4 was defined as the endpoints of i.v. butorphanol infusion (i.e. the time infusion was terminated).

Lower-limb orthopedic surgery is frequently performed with regional anesthesia (23). Despite several advantages, those surgeries are associated with discomfort and worry for the patients. Furthermore, lower-limb orthopedic surgery usually requires to be performed under the tourniquet to achieve a clear operation field. However, application of a tourniquet is a non-physiological process, resulting in an irritable state, local sense of pressure and higher blood pressure after a certain time. Becher et al (24) reported that patients were prone to depression and anxiety after orthopedic injuries, which was also in accordance with our experience at our institution. Stress factors in the operating room and ineffective or patchy blocks may aggravate nervosity and anxiety in patients under regional anesthesia. Thus, sufficient sedation and cooperation of the patient are of great importance.

Procedural sedation, known as monitored anesthesia care, includes methods including a single-dose, intermittent or continuous infusion. However, the different responses 
Table III. Comparison of HR and MAP among different groups.

\begin{tabular}{lcccccc}
\hline A, HR & \multicolumn{7}{c}{} \\
\hline Group & Cases (n) & T0 & T1 & T2 & T3 & T4 \\
\hline High pre-operative anxiety group & 70 & & & & & \\
$\quad$ Butorphanol group & 36 & $88.1 \pm 9.3^{\mathrm{a}}$ & $73.4 \pm 8.2^{\mathrm{b}}$ & $70.4 \pm 9.2^{\mathrm{b}}$ & $68.1 \pm 7.9^{\mathrm{b}}$ & $66.3 \pm 7.7^{\mathrm{b}}$ \\
0.9\% saline group & 34 & $89.8 \pm 8.4^{\mathrm{a}}$ & $88.4 \pm 5.1^{\mathrm{a}}$ & $88.1 \pm 5.6^{\mathrm{a}}$ & $87.0 \pm 7.9^{\mathrm{a}}$ & $86.2 \pm 6.7^{\mathrm{a}}$ \\
Low pre-operative anxiety group & 61 & & & & & \\
Butorphanol group & 32 & $74.0 \pm 7.7$ & $71.7 \pm 6.6^{\mathrm{b}}$ & $69.8 \pm 7.3^{\mathrm{b}}$ & $68.3 \pm 6.2$ & $66.1 \pm 5.8$ \\
$0.9 \%$ saline group & 29 & $73.1 \pm 6.4$ & $72.1 \pm 6.4$ & $71.1 \pm 7.5$ & $70.7 \pm 5.8$ & $70.0 \pm 5.0$ \\
\hline
\end{tabular}

B, MAP

\begin{tabular}{|c|c|c|c|c|c|c|}
\hline Group & Cases (n) & T0 & $\mathrm{T} 1$ & $\mathrm{~T} 2$ & $\mathrm{~T} 3$ & $\mathrm{~T} 4$ \\
\hline High pre-operative anxiety group & 70 & & & & & \\
\hline Butorphanol group & 36 & $96.1 \pm 3.9^{\mathrm{a}}$ & $88.3 \pm 3.2^{\mathrm{b}}$ & $84.8 \pm 4.0^{\mathrm{b}}$ & $82.7 \pm 3.6^{\mathrm{b}}$ & $80.9 \pm 3.6^{\mathrm{b}}$ \\
\hline $0.9 \%$ saline group & 34 & $97.9 \pm 5.7^{\mathrm{a}}$ & $97.1 \pm 4.2^{\mathrm{a}}$ & $96.4 \pm 3.4^{\mathrm{a}}$ & $95.7 \pm 3.3^{\mathrm{a}}$ & $95.0 \pm 3.6^{\mathrm{a}}$ \\
\hline Low pre-operative anxiety group & 61 & & & & & \\
\hline Butorphanol group & 32 & $89.3 \pm 4.8$ & $86.9 \pm 3.9^{b}$ & $83.9 \pm 5.2^{\mathrm{b}}$ & $81.9 \pm 2.8^{\mathrm{b}}$ & $80.5 \pm 2.9^{\mathrm{b}}$ \\
\hline $0.9 \%$ saline group & 29 & $88.5 \pm 5.2$ & $88.2 \pm 4.8$ & $87.3 \pm 3.6^{\mathrm{a}}$ & $86.8 \pm 2.8^{\mathrm{a}}$ & $86.1 \pm 2.8^{\mathrm{a}}$ \\
\hline
\end{tabular}

${ }^{\mathrm{a}} \mathrm{P}<0.05$ vs. low-anxiety butorphanol group. ${ }^{\mathrm{b}} \mathrm{P}<0.05$ vs. the previous time-point. Values are expressed as the mean \pm standard deviation. HR, heart rate; MAP, mean arterial pressure; T0, 10 min after entering the operating room; T1, 5 min after intravenous infusing butorphanol; T2, 10 min after intravenous infusing butorphanol; T3, 15 mins after intravenous infusing butorphanol 15 min; T4, 30 min after intravenous infusing butorphanol.

of patients with different levels of pre-operative anxiety to sedative drugs may result in ineffective or deep sedation (2). In the present study, to better explore the sedative requirements of patients with different pre-operative anxiety scores, butorphanol was administered with a loading dose followed by a maintenance dose. A previous study also reported that continuous i.v. infusion of butorphanol was able to maintain plasma butorphanol concentrations within a stable range, resulting in effective analgesia, and the side effects were reduced during the infusion compared with a single injection of butorphanol (25). The total safe dose of butorphanol that may be given i.v. is $20-40 \mu \mathrm{g} / \mathrm{kg}$ (26). According to the administration method in the present study, the total dose of butorphanol may be guaranteed to be in the safe range when the duration of the operation is $\leq 3.5 \mathrm{~h}$. In the present study, the longest duration of surgery did not exceed $3.5 \mathrm{~h}$ and the total dose of butorphanol was still in the safe range.

Sinha et al (7) reported that butorphanol provided satisfactory sedation, and in the present study, the RSS in patients with high pre-operative anxiety in the butorphanol group was higher than that in patients with high pre-operative anxiety in the $0.9 \%$ saline group at each time-point after infusion. Furthermore, a linear correlation between the duration for the RSS to reach 4 and the APAIS score of patients in the butorphanol groups was determined, and the butorphanol infusion method applied in the present study was as follows: The total dose of butorphanol was administered as a loading dose of $15 \mu \mathrm{g} / \mathrm{kg}$ butorphanol, followed by infusion of $7.5 \mu \mathrm{g} / \mathrm{kg} / \mathrm{h}$.
After substituting the linear regression equation derived from the correlation graph into that for the butorphanol infusion method, the following formula was obtained: Precise dose of butorphanol $(\mu \mathrm{g} / \mathrm{kg})=15.26+(0.14 \times$ APAIS score $)$.

Pre-operative anxiety was also reported to cause fluctuation of hemodynamics and damage to sleep quality, which may be potentially harmful to patients; however, an adequate sedative state in patients may reduce hemodynamic changes and raise the level of patients' satisfaction (27). In the present study, the hemodynamics were kept lower during the operation in MAP and HR in patients with high pre-operative anxiety in the butorphanol group than in patients with high pre-operative anxiety in the $0.9 \%$ saline group. The level of patient satisfaction with conscious i.v. sedation was between agreeable and neither pleasant nor unpleasant for $92.6 \%$ of patients and slightly uncomfortable for $7.4 \%$, which was better than in the patients in the $0.9 \%$ saline groups. The side effects were similar among patients, regardless of the level of pre-operative anxiety. Although the incidence of nausea/vomiting and dizziness in patients with high pre-operative anxiety in the butorphanol group was higher than that in the other three groups, there were still no significant differences among the four groups. None of the patients had respiratory depression or bradycardia in the first $24 \mathrm{~h}$ post-operation.

Sinha et al (7) also demonstrated that butorphanol decreased the post-operative analgesic requirement. Similar to their results, the present study indicated that the VAS 
Table IV. Post-operative parameters in the first $24 \mathrm{~h}$ after operation.

A, Adverse events

\begin{tabular}{|c|c|c|c|c|c|}
\hline \multirow[b]{2}{*}{ Item } & \multicolumn{2}{|c|}{ High pre-operative anxiety group } & \multicolumn{2}{|c|}{ Low pre-operative anxiety group } & \multirow[b]{2}{*}{ P-value } \\
\hline & $\begin{array}{l}\text { Butorphanol group } \\
\qquad(\mathrm{n}=36)\end{array}$ & $\begin{array}{l}0.9 \% \text { saline group } \\
\quad(n=34)\end{array}$ & $\begin{array}{l}\text { Butorphanol group } \\
\qquad(\mathrm{n}=32)\end{array}$ & $\begin{array}{l}0.9 \% \text { saline group } \\
(\mathrm{n}=29)\end{array}$ & \\
\hline Nausea and vomiting & $7(19.4)$ & $6(17.6)$ & $3(9.4)$ & $1(3.4)$ & 0.196 \\
\hline Dizziness & $7(19.4)$ & $3(8.8)$ & $5(15.6)$ & $2(6.9)$ & 0.391 \\
\hline Respiratory depression & $0(0)$ & $0(0)$ & $0(0)$ & $0(0)$ & - \\
\hline Bradycardia & $0(0)$ & $0(0)$ & $0(0)$ & $0(0)$ & - \\
\hline
\end{tabular}

B, Post-operative VAS score

\begin{tabular}{cccr}
\hline Time-point $(\mathrm{h})$ & Butorphanol groups & $0.9 \%$ Saline groups & P-value \\
\hline 1 & $0.90 \pm 0.7$ & $2.79 \pm 0.8$ & $<0.001$ \\
2 & $1.16 \pm 0.6$ & $3.22 \pm 0.7$ & $<0.001$ \\
4 & $1.44 \pm 0.5$ & $3.62 \pm 0.5$ & $<0.001$ \\
6 & $1.79 \pm 0.4$ & $3.76 \pm 0.4$ & $<0.001$ \\
12 & $2.62 \pm 0.6$ & $4.29 \pm 0.8$ & $<0.001$ \\
24 & $3.28 \pm 0.6$ & $5.13 \pm 0.6$ & $<0.001$
\end{tabular}

Values are expressed as the mean \pm standard deviation. Butorphanol groups: High-anxiety butorphanol group and low-anxiety butorphanol group; $0.9 \%$ Saline groups: High-anxiety $0.9 \%$ saline group and low-anxiety $0.9 \%$ saline group. VAS, visual analogue scale.

Table V. Post-operative patient satisfaction.

\begin{tabular}{lccc}
\hline Rating & Butorphanol groups & $0.9 \%$ Saline groups & P-value \\
\hline Agreeable experience & $44(64.7)$ & $29(46)$ & 0.032 \\
Neither pleasant nor unpleasant & $19(27.9)$ & $18(28.6)$ & 0.936 \\
Slightly uncomfortable & $5(7.4)$ & $9(14.3)$ & 0.199 \\
Disagreeable experience & $0(0)$ & $0(11.1)$ & 0.005 \\
Traumatic experience & $0(0)$ & $0)$
\end{tabular}

Values are expressed as the mean \pm standard deviation. Butorphanol groups: High-anxiety butorphanol group and low-anxiety butorphanol group; $0.9 \%$ saline groups: High-anxiety $0.9 \%$ saline group and low-anxiety $0.9 \%$ saline group.

scores were significantly lower in the butorphanol groups as compared with those in the $0.9 \%$ saline groups throughout the first $24 \mathrm{~h}$ post-operation.

The present study has certain limitations that are worth mentioning. First, the RSS scale and APAIS used in the present study are authoritative scales, while the method used to measure the level of patient sedation and pre-operative anxiety were based on the subjective observation of the investigator, leading to a lack of objectivity of data to a certain extent. Furthermore, the proposed formula requires further improvement to determine which way of infusion should be used to rapidly achieve an adequate sedative state. Finally, after application of sedative drugs, there were still two patients with a high pre-operative anxiety score in the butorphanol group who did not reach RSS 4 throughout the operation, which may suggest that the infusion method applied in the present study does not apply to all types of patient.

In conclusion, butorphanol did not only provide an effective sedative and analgesic effect without a significant increase in adverse effects, including nausea, vomiting, bradycardia or respiratory depression, but also provided stable hemodynamic changes during the surgery and higher post-operative satisfaction for patients with pre-operative anxiety. The formula proposed was as follows: Precise dose of butorphanol $(\mu \mathrm{g} / \mathrm{kg})=15.26+(0.14 \times$ APAIS score; adherence to this formula may provide an improvement for patients who exhibit a high level of pre-operative anxiety. If patients with a higher pre-operative anxiety score do not achieve adequate sedation within the calculated total dose, combined use of other sedative drugs should be considered. 


\section{Acknowledgements}

The authors would like to thank Dr Liqiang Zheng from the Department of Statistics, Shengjing Hospital of China Medical University at Shenyang (Shenyang, China) for discussion and advice regarding the statistical analysis of this study.

\section{Funding}

The present study was funded by the Support Plan for Innovative Talents in Liaoning Higher Education Institutions (grant no. 201834).

\section{Availability of data and materials}

All data generated or analyzed during this study are included in this published article.

\section{Authors' contributions}

BS, YY and JZ designed the study. BS, YY, WB, XT and YL performed the study. BS, WB and JZ analyzed the data. BS, YY, WB and JZ prepared the manuscript. All authors contributed to the conception of the study and read and approved the final manuscript.

\section{Ethics approval and consent to participate}

Ethical approval of this study was granted by the Human Research Ethical Committee of Shengjing Hospital (Shenyang, China; IRB registration no. 2018PS254K). Informed consent was obtained from all of the participants.

\section{Patient consent for publication}

Not applicable.

\section{Competing interests}

The authors declare that they have no competing interests.

\section{References}

1. Seifi Z, Beikmoradi A, Oshvandi K, Poorolajal J, Araghchian M and Safiaryan R: The effect of lavender essential oil on anxiety level in patients undergoing coronary artery bypass graft surgery: A double-blinded randomized clinical trial. Iran J Nurs Midwifery Res 19: 574-570, 2014.

2. Osborn TM and Sandler NA: The effects of pre-operative anxiety on intravenous sedation. Anesth Prog 51: 46-51, 2004.

3. Jaw SP, Hoskins B and Ho IK: Opioid antagonists and butorphanol dependence. Pharmacol Biochem Behav 44: 497-500, 1993.

4. Nelson KE and Eisenach JC: Intravenous butorphanol, meperidine, and their combination relieve pain and distress in women in labor. Anesthesiology 102: 1008-1013, 2005.

5. WHO Expert Committee on Drug Dependence: WHO expert committee on drug dependence. World Health Organ Tech Rep Ser i: 1-21, 23-24, 2006.
6. Elcicek K, Tekin M and Kati I: The effects of intravenous dexmedetomidine on regional hyperbaric ropivacaine anesthesia. J Anesth 24: 544-548, 2010.

7. Sinha C, Kaur M, Kumar A, Kulkarni A, Ambareesha M and Upadya M: Comparative evaluation of midazolam and butorphanol as oral premedication in pediatric patients. J Anaesthesiol Clin Pharmacol 28: 32-35, 2012.

8. Mohamed D: American society of anaesthesiologists physical status classification. Indian J Anaesth 55: 111-114, 2011.

9. Moerman N: Psychological aspects of anesthesia. Nederlands Tijdschrift Voor Anesthesiol 2: 61-63, 1996.

10. Goebel S, Kaup L and Mehdorn HM: Measuring pre-operative anxiety in patients with intracranial tumors: The Amsterdam pre-operative anxiety and information scale. J Neurosurg Anesthesiol 23: 297-293, 2011.

11. Wattier JM, Barreau O, Devos P, Prevost S, Vallet B and Lebuffe G: Measure of pre-operative anxiety and need for information with six issues. Ann Fr Anesth Reanim 30: 533-537, 2011 (In French).

12. Moerman N, van Dam FS, Muller MJ and Oosting H: The Amsterdam preoperative anxiety and information scale (APAIS). Anesth Analg 82: 445-451, 1996.

13. Ramsay MA, Savege TM, Simpson BR and Goodwin R: Controlled sedation with alphaxalone-alphadolone. Br Med J 2: 656-659, 1974.

14. Gurajala I, Nikhar SA, Jayaram K and Gopinath R: Regional anesthesia is safe and effective for lower limb orthopedic surgery in patient with renal tubular acidosis and hypokalemia. J Anaesthesiol Clin Pharmacol 34: 117-119, 2018.

15. Tago N, Kanaya N, Nakayama M, Seki S, Kawana S and Nakiki A: Evaluation of midazolam premedication for preoperative anxiolysis. Masui 43: 1520-1523, 1994 (In Japanese).

16. Behrend CJ, Schönbach EM, Vaccaro AR, Coyne E, Prasarn ML and Rechtine GR: Maximum pain on visual analog scales in spinal disorders. Spine J 17: 1061-1065, 2017.

17. Maranets I and Kain ZN: Preoperative anxiety and intraoperative anesthetic requirements. Anesth Analg 89: 1346-1351, 1999.

18. Hong JY, Jee YS and Luthardt FW: Comparison of conscious sedation for oocyte retrieval between low-anxiety and high-anxiety patients. J Clin Anesth 17: 549-553, 2005.

19. Celik F and Ipek S: Evaluation of preoperative anxiety and fear of anesthesia using APAIS score. Eur J Med Res 23: 41, 2018.

20. Aust H, Eberhart L, Sturm T, Schuster M, Nestoriuc Y, Brehm F and Rüsch D: A cross-sectional study on pre-operative anxiety in adults. J Psychosom Res 111: 133-139, 2018.

21. Deol H, Dimtri F, Minaie A, Surani S and Udeani G: Role of Ramsay sedation scale in sedative dosage modulation for Critically-Ill intubated patients. Chest 152: A330, 2017.

22. Strøm T: Sedation in the ICU. Dan Med J 59: B4458, 2012.

23. Ekin A, Donmez F, Taspinar V and Dikmen B: Patient-controlled sedation in orthopedic surgery under regional anesthesia: A new approach in procedural sedation. Braz J Anesthesiol 63: 410-414, 2013.

24. Becher S, Smith M and Ziran B: Orthopaedic trauma patients and depression: A prospective cohort. J Orthop Trauma 28: e242-e246, 2014

25. Sellon DC, Monroe VL, Roberts MC and Papich MG: Pharmacokinetics and adverse effects of butorphanol administered by single intravenous injection or continuous intravenous infusion in horses. Am J Vet Res 62: 183-189, 2001.

26. WHO:34thECDD2006/4.1: Critical review ofBUTORPHANOL. http://www.who.int/medicines/areas/quality_safety/4.1Buthorph anolCritReview.pdf. Accessed February 12, 2012.

27. Tripathi M, Nath SS, Chaudhary A, Singh PK and Pandey CM: Patient controlled sedation during center neuraxial anesthesia. J Postgrad Med 55: 108-112, 2009.

This work is licensed under a Creative Commons Attribution-NonCommercial-NoDerivatives 4.0 International (CC BY-NC-ND 4.0) License. 